\title{
Presença Karajá: biografias e biofilia em uma investigação sobre cultura material
}

\author{
Manuelina Maria Duarte Cândido ${ }^{1}$ \\ Université de Liège
}

Bárbara Freire Ribeiro Rocha ${ }^{2}$ Universidade Federal do Piauí

Resumo: Os Iny Karajá são um povo indígena habitante das margens do rio Araguaia, cujas mulheres são detentoras do modo de fazer das bonecas de cerâmica denominadas ritxoko. Este artigo tem por objetivo apresentar alguns dos primeiros resultados do projeto de pesquisa Presença Karajá: cultura material, tramas e trânsitos coloniais (etapa 1, 2017-2020), e algumas das questões conjunturais e epistemológicas que levaram à realização da Ação de Saúde Indígena Iny/Karajá durante da epidemia de COVID-19.

Palavras-chave: Ritxoko; Projeto Presença Karajá, museus, pandemia COVID-19, saúde indígena.

\footnotetext{
${ }^{1}$ Mestre em Arqueologia (USP) e Doutora em Museologia (ULHT), realizou estágio de pós-doutoramento em Museologia na Universidade Sorbonne Nouvelle. Dirigiu o Departamento de Processos Museais do IBRAM. Chefe de Serviço de Museologia da Universidade de Liège e administradora do Embarcadère du Savoir, professora permanente do PPGAS/UFG. ${ }^{2}$ Mestre em Museologia pelo Programa de Pós-Graduação em Artes, Patrimônio e Museologia (PPGAPM/UFPI, 2017), especialista em Patrimônio, Direitos Culturais e Cidadania (NDH/UFG, 2015), bacharel em Design de Moda pela Faculdade de Artes Visuais (FAV/UFG, 2009). Sócia-diretora da CALÍOPE: projetos e ações patrimoniais.
} 


\title{
Karajá Presence: biographies and biophilia in an investigation of material culture
}

\begin{abstract}
The Iny Karajá are an indigenous people living on the banks of the Araguaia River, whose women have the way of making ceramic dolls called ritxoko. This article aims to present some of the first results of the Presença Karajá research project: material culture, plots and colonial transits (stage 1, 2017-2020), and some of the conjunctural and epistemological issues that led to the Indigenous Health Action Iny Karajá during the COVID-19 epidemic.
\end{abstract}

Keywords: Ritxoko; Presença Karajá project; museums; pandemic COVID-19; indigenous health.

\section{Presencia Karajá: biografías y biofilia en una investigación de la cultura material}

Resumen: Los Iny Karajá son un pueblo indígena que habita las márgenes del río Araguaia, cuyas mujeres son las dueñas de la forma de hacer muñecos de cerámica llamados ritxoko. Este artículo tiene como objetivo presentar algunos de los primeros resultados del proyecto de investigación Presença Karajá: cultura material, parcelas y tránsitos coloniales (etapa 1, 2017-2020), y algunas de las cuestiones coyunturales y epistemológicas que llevaron a la Acción de Salud Indígena Iny Karajá durante la epidemia de COVID-19.

Palabras clave: Ritxoko; Proyecto Presença Karajá; museos; pandemia COVID19; salud indígena. 
Como eram tranquilos os dias, em que sabíamos exatamente o que era um museu e aquilo que não era. Quando os museus serviam apenas para mostrar ou glorificar a história de qualquer coisa, ou quando só mostravam as suas coleções e arquivos, herdados, coletados, comprados, saqueados ou oferecidos. Os

Museus eram tranquilos enfrentando apenas os problemas de armazenamento, preservação $e$ eventualmente de documentação.

(MOUTINHO, 2014)

$\mathrm{E}$ ste artigo tem por objetivo apresentar alguns dos resultados preliminares do projeto de pesquisa Presença karajá: cultura material, tramas e trânsitos coloniais (etapa 1, 2017-2020), sediado na Universidade Federal de Goiás (UFG) e que conta com o apoio do Museu Antropológico da UFG, do Núcleo de Estudo de Antropologia, Patrimônio, Memória e Expressões Museais (NEAP) e do Grupo de Estudo e Pesquisa Museologia e Interdisciplinaridade (GEMINTER). Integraram a equipe, desde o início, pesquisadoras e estudantes de diferentes cursos da UFG, da Escola de Ciência da Informação da UFMG e da Universidade de Évora, Portugal3. Este texto é, especialmente, um registro dos primeiros momentos do projeto, que poderá ser futuramente comparado com outros períodos, ainda a serem relatados.

O objeto desta pesquisa interdisciplinar é o mapeamento, identificação e análise de coleções de bonecas cerâmicas Karajá (ritxoko) presentes em acervos de museus brasileiros e estrangeiros, com vistas a elaborar cartografias e biografias destas coleções, notadamente de seus processos de formação e dos contatos de pesquisadores e instituições com os grupos indígenas, além de estudar adornos corporais e indumentárias das bonecas. Assim, buscamos compreender o percurso das ritxoko desde sua produção e uso nas aldeias, até os processos de troca ou comercialização que as levou para o interior dos acervos das instituições museológicas.

O recorte no âmbito da cultura material karajá privilegiou as ritxoko, bonecas de cerâmica antropomorfas, inscritas em 2012 em dois Livros de Registro do Patrimônio Imaterial: 1) Saberes e práticas associados aos modos de fazer bonecas Karajá e 2) Ritxoko - expressão artística e cosmológica do povo karajá pelo Instituto do Patrimônio Histórico e Artístico Nacional (IPHAN), a partir da fundamentação formulada no dossiê Bonecas Karajá: arte, memória e identidade indígena no Araguaia (LIMA, et al., 2011).

O Museu Antropológico da Universidade Federal de Goiás (MA-UFG), que desde sua origem, em 1969, trabalha com os povos indígenas, notadamente os Iny Karajá, formou ao longo destes anos um vasto acervo de cultura material karajá, sobre o qual nos debruçamos em busca das peças denominadas ritxoko,

3 A equipe foi inicialmente formada pelos seguintes integrantes: Profa. Dra. Nei Clara de Lima (Antropóloga, Professora aposentada da FCS/UFG e ex-Diretora do Museu Antropológico da UFG); Profa. Dra. Manuelina Maria Duarte Cândido (então professora do Curso de Museologia, FCS/UFG); Profa. Dra. Ema Cláudia Ribeiro Pires (Profa. Auxiliar no Departamento de Sociologia, Universidade de Évora); Profa. Dra. Rita Andrade (Curso de Design de Moda, FAV/UFG); Dibexia Karajá - Ceramista e Discente do Curso de Licenciatura Intercultural Indígena da UFG; Milena de Souza (então Discente de Museologia FCS/UFG); Indyanelle Marçal Garcia di Calaça (então Mestranda em Arte e Cultura Visual FAV/UFG) e Rejane de Lima Cordeiro (então Discente de Museologia FCS/UFG); Vinicius Santos da Silva (então Discente de Museologia da UFMG em intercâmbio na Universidade de Évora); Ana Cristina Santoro (Conservadora e Restauradora de Bens Culturais - Museu Antropológico/UFG) e Markus Garscha (Fotógrafo). Depois de muitas outras composições, o grupo hoje é formado por quase duas dezenas de pessoas, sediadas em diversos países e diferentes estados do Brasil. 
que totalizam mais de sete centenas, sendo algumas peças ainda em fase de registro e incorporação ao acervo.

Além do Museu Antropológico da UFG, nosso ponto de partida, cartografamos e buscamos compreender a dispersão geográfica e os múltiplos interesses que as levaram a estar presentes hoje em tantas instituições brasileiras 4 e estrangeiras 5 , levantamento este ainda em curso, mas que já alcançou 75 museus em 16 países. Nesta primeira etapa foram particularmente desenvolvidos a ampliação da cartografia de instituições que possuem as ritxoko e o contato com algumas delas para um trabalho mais sistemático de documentação destes acervos, com a criação de um Instrumento Comum de Coleta dos Dados da Pesquisa (IC), que permite uniformizar e futuramente comparar os dados registrados de maneira muito variada de uma instituição a outra. Consideramos necessário mais tempo para estudos aprofundados sobre os trânsitos coloniais envolvidos na formação das coleções, razão pela qual optamos por ampliar o projeto para a etapa 2 (20212024).

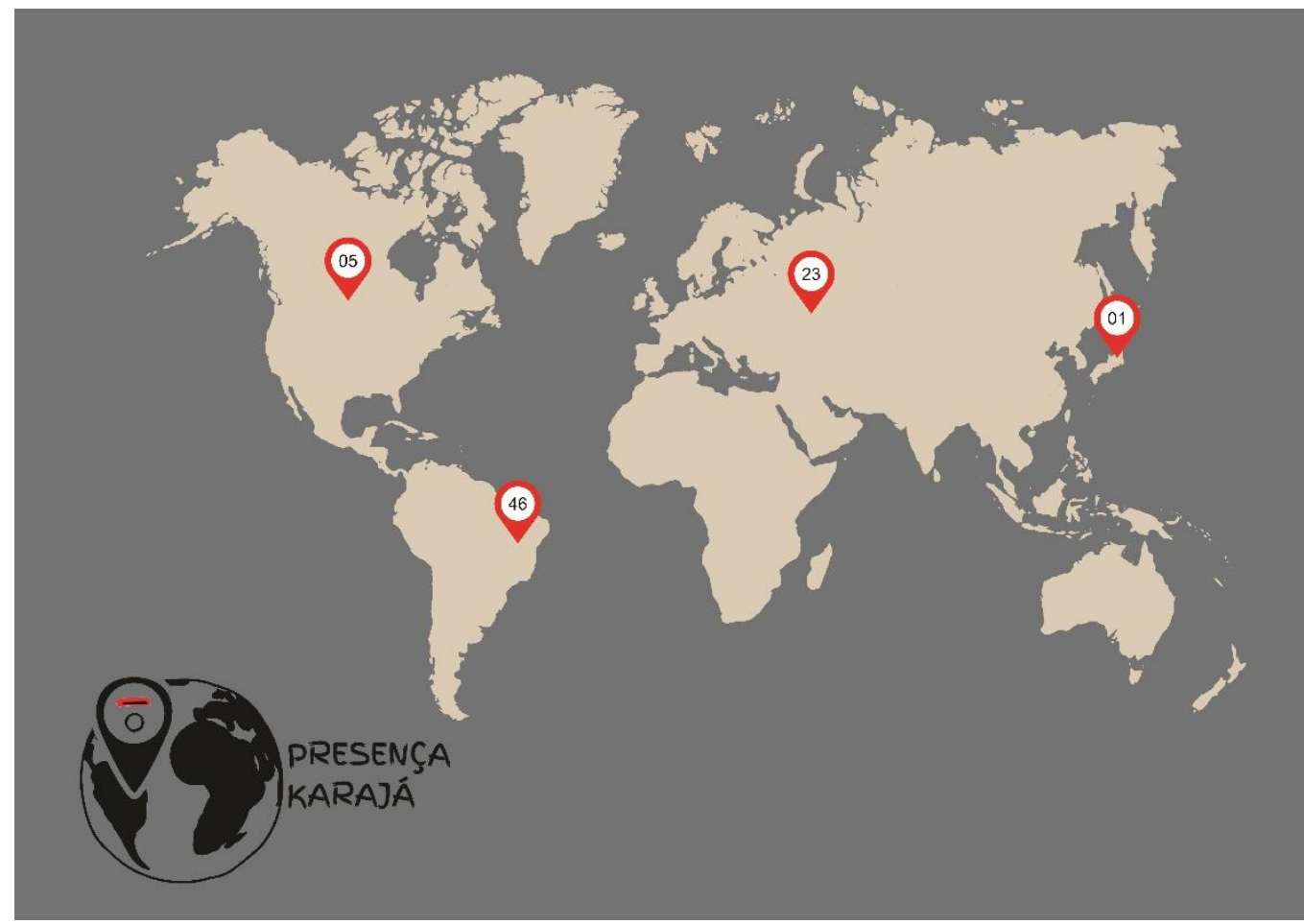

Figura 1: Mapa global com quantitativo de instituições museais que possuem bonecas Karajá em seus acervos. Fonte: Acervo do Projeto Presença Karajá. Elaboração: Bárbara Freire e Manuelina Duarte

O encontro dos rios Araguaia-Tocantins é uma região estratégica para os trânsitos por via fluvial desde tempos imemoriais, favorecendo o contato e despertando múltiplos interesses, notadamente comerciais. Das várias expedições estrangeiras enviadas ao Brasil muitas passaram pela região em tela (WHAN,

\footnotetext{
4 Entre outras: Museu Goiano Zoroastro Artiaga, Goiânia - GO; O então Pavilhão das Culturas Brasileiras, hoje denominado Museu das Cultura Brasileiras - Secretaria Municipal de Cultura - São Paulo SP; Museu de Arqueologia e Etnologia da Universidade de São Paulo - São Paulo SP; Museu Paraense Emílio Goeldi - Belém, PA; Centro Nacional do Folclore e Cultura Popular - Rio de Janeiro, RJ; Museu do Índio - Rio de Janeiro, RJ; Museu Nacional - Rio de Janeiro, RJ.

5 Museu Nacional de Etnologia - Lisboa, Portugal; Museu do Quai Branly - Paris, França; Museu de Etnologia de Viena - Viena, Áustria; Museu de Etnologia de Basel, Suíça; Museu Nacional Pigorini de Pré-História e Etnografia - Roma, Itália; Grassi Museum (Museu Etnográfico de Leipzig) - Alemanha; Museu de Etnologia de Berlim - Alemanha; Smithsonian Institution, Washington, Estados Unidos.
} 
2010; CAMPOS, 2002). Entre os agentes a destacar, citamos os etnólogos alemães Paul Ehrenreich (1888-1889) e Fritz Krause (1911, 1940, 1943) que realizaram coletas que vieram a integrar posteriormente os acervos do Ethnologisches Museum - Berlim e do Grassi Museum - Museum für Völkerkunde Leipzig, na Alemanha (LIMA FILHO, 2017; CAMPOS, 2002; HARTMANN, 1973). Podemos mencionar ainda uma Missão Dominicana que coletou para o Museo Pigorini, da Itália, ainda no século XIX, C. H. Hofbauer, que coletou para o Museu Paulista em 1904; Franz Adam que lhe acresceu 118 peças em 1909; Darcy Bandeira de Melo (em 1937); W. Tiede, que formou uma coleção (1938/39) com curta passagem pelo Museu Dom José de Cuiabá (MT) antes de juntar-se às demais no Museu Paulista; Herbert Baldus, fundador da Seção de Etnologia do Museu Paulista em 1946; e Harald Schultz que lhe fez acréscimos em 1947 e 48, 1956 e 1960 (CAMPOS, 2002).

As coleções do Museu Nacional do Rio de Janeiro, foram inicialmente formadas pelo bispo de Goiás em meados dos anos 1870 e recebeu acréscimos, entre outros, do estadunidense William Lipkind em 1938 e 1939 (CAMPOS, 2002).

Estas trajetórias de formação de coleções, ainda em estudo, já permitem perceber locais ou pessoas de convergência, que intervêm na formação de mais de uma coleção de diferentes museus. São necessárias mais pesquisas, entretanto, para tentar localizar informações sobre os agentes do lado indígena, cujos nomes raramente foram registrados na documentação dos acervos, sejam as produtoras, ceramistas, sejam intermediários locais para a coleta ou venda destas peças.

No Museu Antropológico da UFG algumas coleções foram registradas em associação a nomes como Acary Passos de Oliveira (diretor da instituição entre 1970 e 1979) e Edna Luísa de Melo Taveira (de 1987 a 1992). Há na documentação do acervo, porém, o registro de coleções com nomes indígenas, como Kutaria Karajá (1987); Marwel Tuilá Karajá (1988); Ijesebery Karajá (1988); Daniel Coxini Karajá (1988) e Kueredji Karajá (1990). Por serem em sua maioria homens, é uma pista de pesquisa que indica possíveis intermediários para a aquisição de peças pelo museu, já que não seriam, provavelmente, ceramistas ${ }^{6}$.

No que tange ao desenvolvimento do Projeto Presença Karajá, produtos decorrentes desta primeira etapa da pesquisa como artigos científicos, apresentações em eventos e a publicação de pelo menos um dossiê temático, são considerados como elementos de promoção das coleções que, em consonância com a Recomendação da UNESCO (2015), contribuem com o conjunto de ações de salvaguarda dos bens registrados conforme protocolos do IPHAN. Mesmo que este seja um estudo exploratório e em seu escopo amplo não chegue a aprofundar análises de coleções específicas, o mapeamento e divulgação da existência de coleções até então pouco conhecidas em seu conjunto, estimulará novas pesquisas e, em cada instituição, possivelmente uma revisitação de acervos por vezes secundarizados, provocando movimentos de revisão da documentação museológica, registro fotográfico ou mesmo realização de novas exposições.

Por meio dos artefatos já musealizados, podemos contribuir para a valorização dos saberes, práticas e expressões do povo Iny, em cuja população resistem as ceramistas detentoras dos saberes que envolvem a produção, da coleta do barro à modelagem, queima e pintura (WHAN, 2010; FARIAS, 2014, entre outros) e até mesmo a comercialização das ritxoko. Cabe ressaltar que em todo este processo, o protagonismo é feminino.

${ }^{6}$ Esta divisão de gêneros é reputada como muito marcada e os homens costumam se dedicar ao artesanato em madeira, sejam canoas e remos, ou bonecas com outras feições e nesta matéria-prima, chamadas kawa kawa. 
O povo Iny Karajá7 habita 18 aldeias às margens do rio Araguaia, abrangendo os estados de Goiás, Tocantins, Mato Grosso e Pará, com população aproximada de quatro mil pessoas ${ }^{8}$.

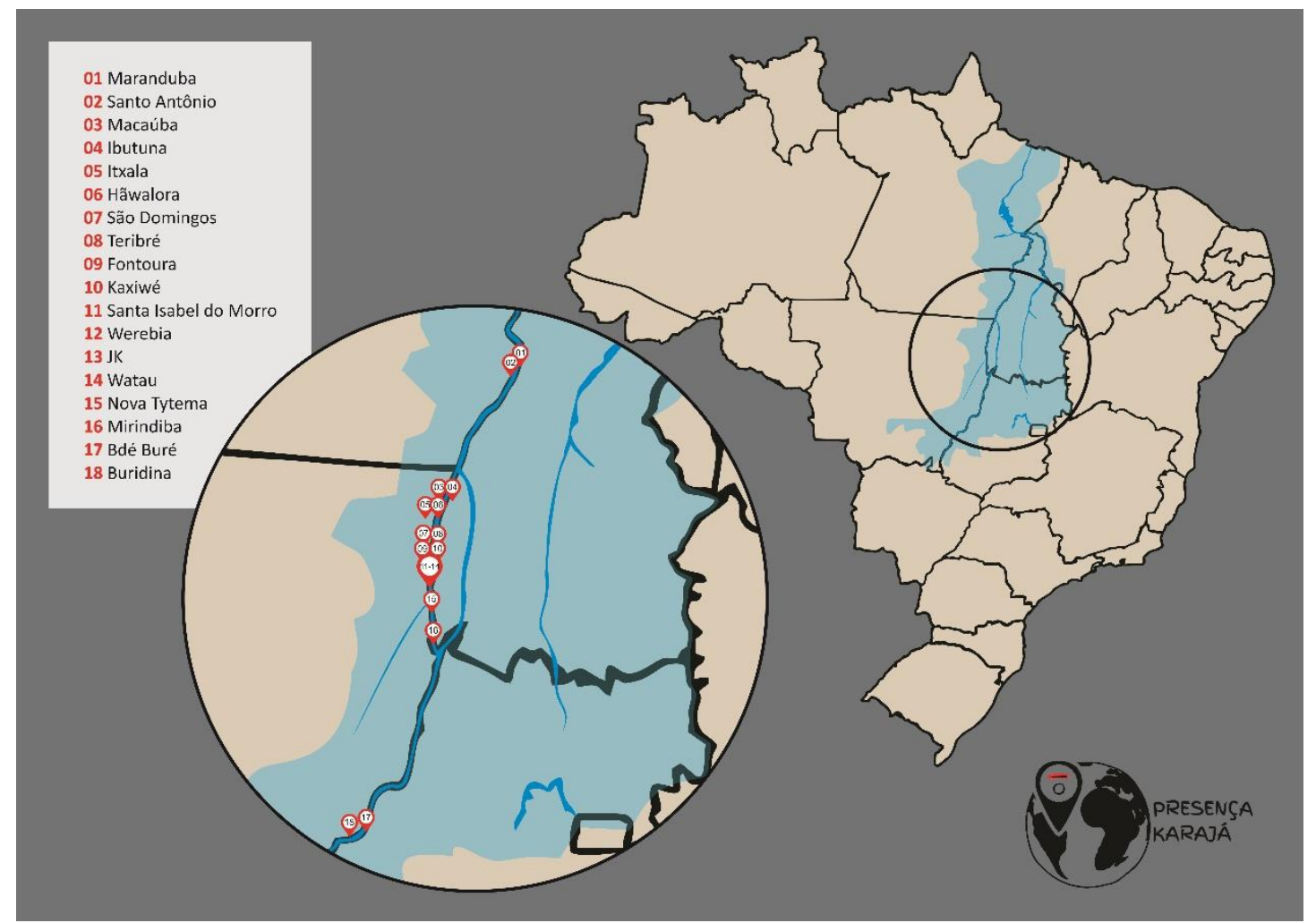

Figura 2: Mapa do Brasil com a Bacia Hidrográfica Tocantins-Araguaia, demarcando os rios Araguaia (lado esquerdo) e Tocantins (lado direito). Em destaque, a localização das comunidades indígenas Iny Karajá. Fonte: Acervo do Projeto Presença Karajá. Elaboração: Bárbara Freire e Manuelina Duarte

A bacia hidrográfica Tocantins Araguaia possui $918.273 \mathrm{~km}^{2}$ (aproximadamente $11 \%$ do território nacional) abrangendo as regiões Centro-Oeste e Norte do país, com os estados de Goiás (26,8\%), Tocantins (34,2\%), Pará (20,8\%), Maranhão (3,8\%), Mato Grosso (14,3\%) e o Distrito Federal (o,1\%). Os principais rios da bacia são o Rio Tocantins e Rio Araguaia, que desaguam no Oceano Atlântico. $\mathrm{O}$ rio Araguaia possui aproximadamente $2.600 \mathrm{~km}$ de extensão. Nele se encontra a maior ilha fluvial do mundo, Ilha do Bananal, com cerca de $20.000 \mathrm{~km}^{2}$. É nesta ilha, banhada do lado direito pelo rio Araguaia e do lado esquerdo pelo rio Javaé, que se encontra a maior concentração das comunidades indígenas Karajá, ou quatorze de suas dezoito aldeias. Instituída como reserva de preservação permanente em 1959, integrando o Parque Nacional do Araguaia e o Parque Indígena do Araguaia9 (Caderno da Região Hidrográfica do Tocantins-Araguaia, 2006).

O rio Araguaia, conhecido entre os Iny Karajá como Berohoky (o grande rio), é o principal elemento da cosmologia Karajá, que são habitantes seculares de suas margens, com registros aproximados de, pelo menos, 800 anos. A construção social e imagética, do modo de viver e dos modos de fazer das comunidades Karajá

\footnotetext{
7 Iny é sua autodenominação, e significa "nós", enquanto Karajá é a denominação não indígena, significando, segundo Krause, "macaco grande". Disponível em: https://pib.socioambiental.org/pt/Povo:Karaj\%C3\%A1. Acesso em: $16 / 09 / 2020$.

8 Povos Indígenas no Brasil - quadro geral dos povos. Instituto Sociambiental - ISA. Disponível em: https://pib.socioambiental.org/pt/Quadro Geral dos Povos. Acesso em: 16/09/2020.

${ }_{9}$ Disponível em: https://terrasindigenas.org.br/pt-br/terras-indigenas/3592. Acesso em: 16/09/2020.
} 
estão diretamente ligadas ao rio (LIMA, et al., 2011). Como podemos observar no mito formador Karajá:

\begin{abstract}
eles moravam numa aldeia, no fundo do rio, onde viviam e formavam a comunidade dos Berahatxi Mahadu, ou povo do fundo das águas. Satisfeitos e gordos, habitavam um espaço restrito e frio. Interessado em conhecer a superfície, um jovem Karajá encontrou uma passagem. Fascinado pelas praias e riquezas do Araguaia e pela existência de muito espaço para correr e morar, o jovem reuniu outros Karajá e subiram até a superfície. Tempos depois, encontraram a morte e as doenças. Tentaram voltar, mas a passagem estava fechada, e guardada por uma grande cobra, por ordem de Koboi, chefe do povo do fundo das águas. Resolveram então se espalhar pelo Araguaia, rio acima e rio abaixo. Com Kynyxiwe, o herói mitológico que viveu entre eles, conheceram os peixes e muitas coisas boas do Araguaia. Depois de muitas peripécias, o herói casou-se com uma moça Karajá e foi morar na aldeia do céu, cujo povo, os Biu Mahadu, ensinou os Karajá a fazer roças. (LIMA FILHO, 1994 apud RESENDE, 2011: 8-9)
\end{abstract}

Do rio é retirada a principal matéria-prima dos objetos de cerâmica, a argila. O modo de fazer cerâmica é um ofício exclusivamente feminino, transmitido pelas gerações de mulheres Karajá, por meio da relação entre terra (suu), argila (suu kurá) e mulher (hawyky), desde a coleta da argila, preparo da massa de modelagem, modelagem, secagem, alisamento, queima, coleta e preparo dos pigmentos e pintura dos objetos (CAMPOS, 2007). As bonecas Karajá (ritxoko) são originalmente, brinquedos de meninas, por meio dos quais transmitem valores sociais da cultura karajá, como as fases da vida e seus respectivos ritos de passagem. Podem ainda retratar cenas do cotidiano e rituais, como também seres mitológicos e sobrenaturais, como é possível ver na imagem a seguir:

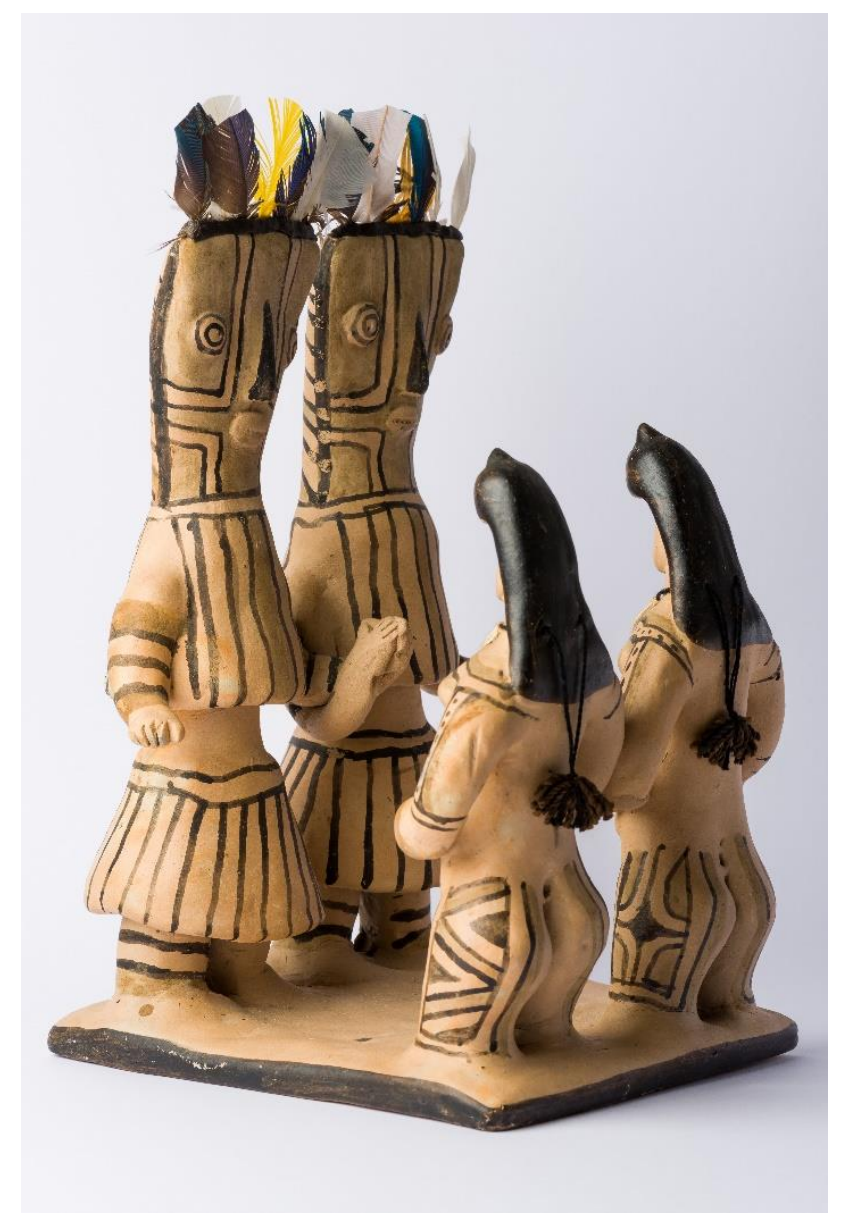


A imagem acima representa uma dança ritual do povo Iny Karajá também realizada entre os Javaé. As máscaras rituais em fibra vegetal que cobrem todo o corpo são vestidas por jovens homens cuja identidade é mantida em segredo por alguns poucos homens da aldeia. Estes jovens são escolhidos por suas qualidades e, ao portá-las, têm a estas acrescidos poderes mágicos ancestrais. Eles andam em pares e aparecem para os jovens meninos no ritual de iniciação masculino denominado Hetohoky, mas a cena representada na figura acima é um momento especial de encontro com duas moças virgens que executam a chamada Dança do Aruanã. O movimento das mãos sobre o ventre atrai fertilidade para as aldeias e é rememorado por mulheres mais velhas, como em nosso encontro com Iracy Karajá na aldeia Buridina, em setembro de 2017. Na ocasião, as indígenas nos mostraram alguns adornos corporais utilizados na dança e simularam a performance.

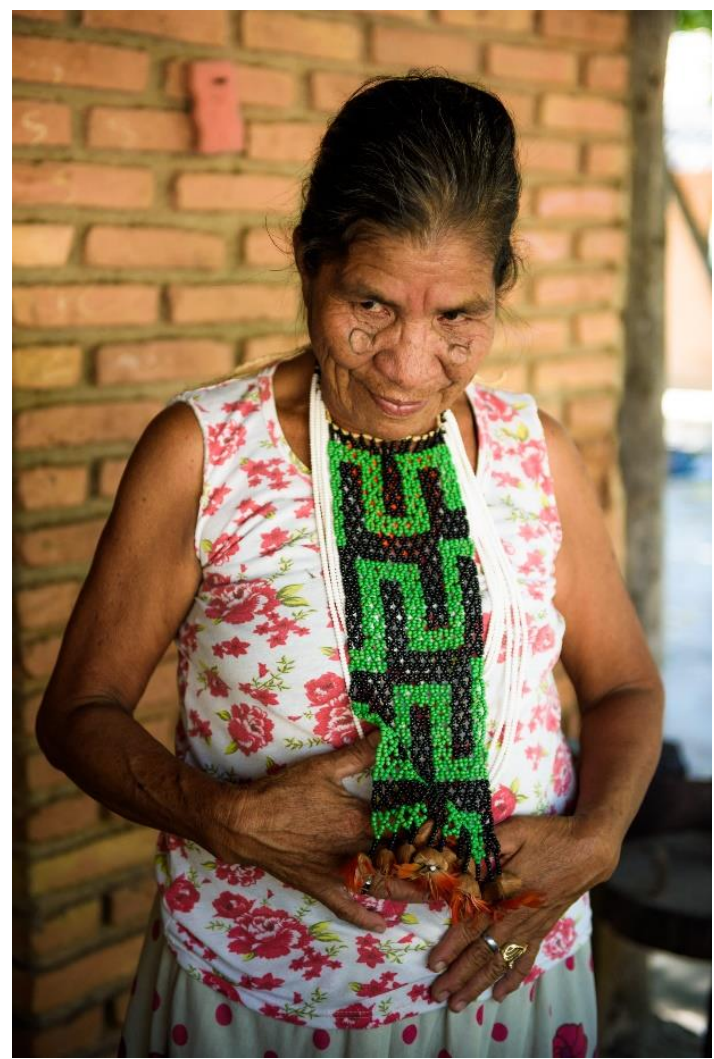

Figura 4: Visita à aldeia Buridina em Aruanã (GO), setembro de 2017. Iracy Karajá demonstra o movimento da Dança do Aruanã. Fonte: Acervo do Projeto Presença Karajá. Foto: Markus Garscha

A peça representada na figura o3 foi inventariada no Museu Antropológico da UFG com o número 90.03.01, o que nos informa que seu ano de entrada para a coleção foi 1990. Ela é particularmente importante para o projeto pelo que suscitou de diálogo com a indígena Dibexia Karajá, integrante de nossa equipe de pesquisa, em agosto de 2017. Dibexia é uma jovem moradora da aldeia de Santa Isabel do Morro que cursa a Licenciatura Intercultural Indígena na UFG e como tal, alterna períodos de aulas na aldeia e na capital de Goiás. Ela tem particular interesse na língua materna, tema de sua pesquisa para o Trabalho de Conclusão de Curso, mas também pratica a execução de peças em cerâmica. Em uma de suas estadas em Goiânia, nós a convidamos a conhecer um espaço ainda inédito para ela, a reserva técnica do Museu Antropológico da UFG.

Vale dizer que as ritxoko apareciam com destaque em dois momentos diferentes da exposição de longa duração da instituição naquele momento, intitulada 
Lavras e Louvores, e inaugurada em 2006. Na seção Lavras, relacionada ao mundo do trabalho, as ritxoko que aparecem são cenas de trabalho doméstico, caça, transporte em canoas, parto e funeral, entre outras. Na seção Louvores, voltada ao mundo das festas e da ritualidade, encontram-se as ritxoko que representam seres sobrenaturais. A peça 90.03.01, entretanto, que representa uma cena completa da Dança do Aruanã, não aparece na exposição, que é bastante visitada pelos indígenas em suas vindas a Goiânia, mas na reserva técnica. Neste espaço Dibexia fez fotos com seu celular e aproximou-se das peças, não somente ritxoko, que pudemos visualizar, embora naquele momento nada tenha sido retirado do seu lugar nos armários deslizantes. Algumas gavetas foram abertas pelo pessoal técnico do museu e os papéis que protegiam alguns objetos delicadamente deslocados para permitir a visualização. Dibexia ficou muito impressionada com esta peça em especial, e ao saber que ela fora uma das fotografadas nas sessões de trabalho do projeto no mês anterior (figura 3), solicitou: "manda a foto dela para mim, eu vou tentar fazer". Segundo a ceramista, ela ainda não havia visto nenhuma ritxoko com esta representação.

$\mathrm{O}$ agenciamento estimulado pelas possibilidades de retorno ao menos digital destes acervos ao povo Iny Karajá é algo que terá mais destaque na etapa 2 (20212024) do Projeto Presença Karajá, malgrado as dificuldades práticas de um projeto sem financiamento. Para tal, estamos em diálogo com a produção do conhecimento no campo da Museologia Social e do que ela bebe nas teorias decoloniais (MORAES WICHERS, 2019), além de contar em nossa equipe com pesquisadores Iny Karajá.

O episódio supracitado reforça a importância do projeto e de seu trabalho de mapeamento, registro e difusão das coleções de ritxoko musealizadas desde pelo menos o final do século XIX, como estratégia também de facilitar o acesso dos e das indígenas a estas importantes referências culturais, o que será intensificado na próxima etapa do projeto.

Nossa metodologia na $1^{\text {a }}$ etapa do projeto, envolve levantamento bibliográfico e em diversas fontes como catálogos, sites e bancos de dados de museus; checagem da documentação museológica das bonecas, contribuindo com o museu, quando possível, para cotejamento e complementação de informações em interlocução com as próprias ceramistas; realização do registro fotográfico de coleções que ainda não o possuem; descrição e análise das bonecas com vistas à identificação de singularidades em sua indumentária (incluídos aí adornos e pinturas corporais); elaboração de biografias dos conjuntos de artefatos que tracem seus percursos da aldeia aos museus, buscando identificar os sujeitos e os processos envolvidos na circulação de saberes sobre as bonecas karajá.

Como primeiros resultados, além da visibilidade estimulada por meio de alguns artigos e comunicações científicas, o projeto já contribuiu para a revisão da documentação museológica de algumas instituições detentoras destas coleções, como Museu Antropológico da UFG, Museu Goiano Zoroastro Artiaga, Centro Cultural Jesco Puttkamer (estes três em Goiânia) e Museu das Culturas Brasileiras, em São Paulo. No Museu Antropológico da UFG a equipe do projeto realizou, voluntariamente, o registro fotográfico profissional de 240 peças, totalizando cerca de 800 fotografias. 


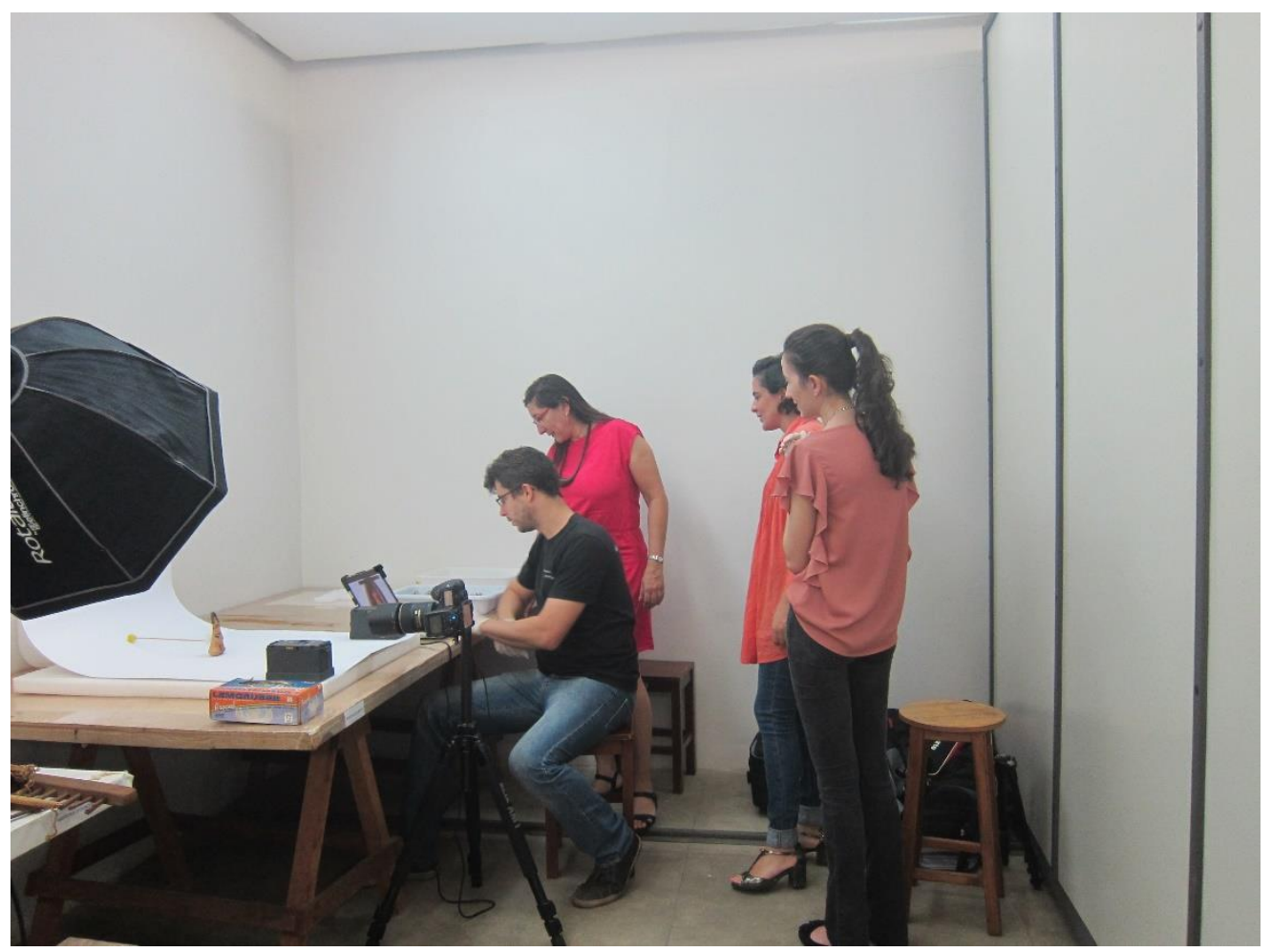

Figura 5: Registro fotográfico de parte do acervo do Museu Antropológico da UFG. Fonte: Acervo Museu Antropológico da UFG. Foto: Ana Cristina Santoro

Assim, contamos contribuir para a proteção e promoção de coleções musealizadas de bonecas karajá, como forma de valorizar a diversidade cultural e especialmente as comunidades detentoras deste rico patrimônio imaterial, retraçando trajetórias de patrimonialização de bens imateriais e da musealização da cultura material a eles associada, por vezes em rotas de afastamento ou de colisão, em um sentido de aproximação e mútua colaboração.

Nos últimos meses, além de prosseguirmos nos trabalhos ligados às diferentes coleções, seus percursos de formação, a biografia das coisas colecionadas e aos registros que os museus possuem de informações sobre elas, iniciamos a ação denominada Ação de Saúde Indígena Iny Karajá, com o objetivo de arrecadar doações para a produção e entrega de máscaras reutilizáveis com vistas à proteção do povo Iny Karajá durante a pandemia da Covid-19.

Obviamente, nada disto fazia parte dos objetivos iniciais do projeto, que em sua dinâmica respeita e procura atender tanto possibilidades que surgem como desafios inesperados. A pandemia do novo coronavírus foi realmente algum imprevisto e que nos confrontou com questões relacionadas aos compromissos éticos, profissionais e políticos dos componentes desta equipe.

O que nos moveu desde o início por perceber de maneira integrada o patrimônio material e o imaterial, este sendo intrinsecamente ligado os grupos detentores de quem depende sua manutenção, o que nos levava à compreensão de que o maior patrimônio são as vidas. Vivemos um momento de crise política, econômica e institucional, em que o desmonte das políticas para a área da cultura e para a proteção de comunidades tradicionais, como os indígenas, caminham lado a lado, desaguando em um abandono quase completo. Por outro lado, nossa vivência no campo da Museologia alertava: a Museologia que não serve para a vida, não serve para nada (Declaração de Córdoba, MINOM1o, 2017). 
Chagas $(2011 ; 2015)$ vem defendendo a noção de museu biófilo em contraponto aos museus necrófilos, feitos "para aprisionar o passado e aprisionar os seres e as coisas no passado e na morte" (CHAGAS, 2011: 7). Usamos biofilia no presente texto neste sentido de interesse pela vida e por sua proteção. Entender que o projeto Presença Karajá pode se articular à luta política indígena de resistência à necropolítica (MBEMBE, 2006) e assumir uma função concreta em suas vidas, não é afastar-se da Museologia, é um aprofundamento de escolhas sobre qual Museologia queremos exercer.

As ritxoko podem ser compreendidas também estratégias de cura e demonstração de resiliência quando permitem, segundo Rodrigues (2015) transformar dor em arte, possibilitando alguma "sustentação moral e cultural" diante das grandes perdas e rupturas deste grupo após o contato: "tanto como ceramistas quanto como oradoras, ao que tudo indica, as mulheres têm estado envolvidas costumeiramente com a difícil tarefa de lapidar a dor coletiva, seja de forma artística, como na atividade oleira, seja de forma catártica, como nos choros rituais (RODRIGUES, 2015: 15).

Mais uma vez fustigados por doença trazidas pelos torí, os Iny Karajá sofreram duras perdas na pandemia de COVID-19. Logo em seu início, antes mesmo que algum caso fosse registrado entre estes indígenas e em uma de nossas reuniões regulares para preenchimento online do Instrumento Comum referente a algum dos muitos acervos com os quais estamos trabalhando (por volta do começo de maio de 2020), decidimos que era urgente fazer alguma ação de combate à pandemia entre os Iny Karajá.

A Ação de Saúde Indígena Iny Karajá foi então concebida para realização por integrantes Projeto Presença Karajá, contando ainda com o apoio da Faculdade de Artes Visuais da UFG, por meio do seu Grupo de Pesquisa Indumenta: dress and textiles studies in Brazil. Foi criado um financiamento coletivo online, para coleta de doações. Resumidamente, alcançamos angariar cerda de vinte mil reais, o que permitiu adquirir e distribuir entre as diferentes aldeias Iny Karajá itens essenciais para a prevenção à COVID e também, à medida que a epidemia avançava, contribuir para melhor equipar os agentes de saúde já atuando em casos de contaminação e adoecimento. Os itens distribuídos foram 2.700 máscaras em tecido, 1000 sabonetes em barra, 200 máscaras para procedimentos, 70 protetores faciais, 25 pares de botas impermeáveis, 14 termômetros digitais a laser e 10 oxímetros digitais. A maior parte das entregas foi intermediada pelo Coletivo de $\mathrm{Mu}-$ lheres Iny Mahadu.

Registramos ainda que 700 das máscaras em tecido foram adquiridas junto à Associação de Mulheres Indígenas Sateré-Mawé, de Manaus (AM), o que permitiu que uma parte do recurso também apoiasse este outro grupo indígena. As outras 2000 foram adquiridas por meio de uma plataforma chamada Fashion Masks, que se apresenta da seguinte forma:

O Instituto REsocial fundou o Fashion Masks com o objetivo de dar vez e voz às costureiras. Cada compra é uma forma importante de apoio ao movimento, cada entrega é parte da história de alguém junto à máquina de costura, cada selo carrega o nome da pessoa por trás da confecção do produto. Modas passam, o Fashion Masks continua.

(...)

Quando o acesso às máscaras de proteção foi um dos problemas decorrentes da escalada do coronavírus no Brasil, a rede do Fashion Masks se mobilizou pela primeira vez. Em cinco meses, a renda arrecadada pelo projeto alcançou o valor de $\boldsymbol{R} \boldsymbol{\$}$ 834.808,25. Hoje, desenvolvendo diferentes produtos no setor têxtil, o Fashion 
Masks conecta a experiência das costureiras a novas demandas e hábitos de consumo, mas o propósito do movimento segue sendo o mesmo, através do trabalho, promover a inclusão social."11.

Esta plataforma, portanto, criada expressamente durante a pandemia para facilitar o acesso de quem desejasse comprar máscaras de tecido e as costureiras, remunerando-as com um preço mais junto, ligeiramente acima do praticado no mercado, foi nossa primeira opção, mas diversificamos os fornecedores ao sabermos da produção realizada pelas indígenas Sateré-Mawé.

A escolha dos fornecedores procurou, na medida do possível, privilegiar iniciativas de cunho social, como fizemos com a aquisição das máscaras, ainda que a dificuldade da logística tenha atrasado muito a entrega, incluindo uma greve dos Correios no meio do processo. Embora em geral as variáveis qualidade e preço fossem muito ponderadas a partir da realização dos orçamentos entre diferentes fornecedores, no caso dos equipamentos de saúde, em várias situações optamos por pagar mais caro e escolher o fornecedor que entregasse mais rápido, devido à urgência. Optamos comumente pelo que houvesse para pronta entrega na cidade de Goiânia, a partir de onde era possível enviar as encomendar de carro ou ônibus direto para Aruanã (GO) ou São Félix das Barreiras (MS), bases a partir das quais a distribuição poderia ser realizada. Contamos especialmente com apoio logístico da Casa de Saúde Indígena - CASAI Goiânia ${ }^{12}$ e do Distrito Sanitário Especial Indígena - DSEI Araguaia ${ }^{13}$ para envios mais urgentes para São Félix do Araguaia, evitando os correios, que foram usados finalmente, somente para trânsito das máscaras de tecido entre Manaus, sede da Associação de Mulheres Indígenas Sateré-Mawé e as aldeias de Santa Maria das Barreiras no Pará e de Aruanã, em Goiás, onde não havia ainda casos de COVID-19.

Com esta ação, buscamos extrapolar os objetivos iniciais do projeto ligados à biografia de exemplares da cultura material para agir em uma situação que chamamos aqui de biofilia como contraponto à necropolítica que grassa no planeta, notadamente no Brasil. É preciso, diante da realidade atual e da pandemia, assumir a defesa da vida como bem e patrimônio maior, sem o que processos outros de musealização e de preservação são esvaziados de sentido. Trata-se de evitar a "ilusão museal" que toma indígenas como "fósseis vivos" (OLIVEIRA e SANTOS, 2019: 12) e aprofundar aspectos colaborativos em nossas práticas de pesquisa. Destarte, reforçamos o compromisso com a defesa da vida e do patrimônio como motor para a ação: "O patrimônio é usado não apenas para simbolizar, representar ou comunicar. O patrimônio é bom para agir.” (GONÇALVES, 2003: 27).

Recebido em 27 de setembro de 2020. Aprovado em 10 de janeiro de 2021.

${ }^{11}$ https://www.fashionmasks.org/. Acesso em 03 de setembro de 2020.

${ }^{12}$ Instituição responsável pelo apoio, acolhimento e assistência aos indígenas encaminhados à Rede de Serviços do Sistemas Único de Saúde - SUS.

${ }_{13}$ Unidade gestora do Subsistema de Atenção à Saúde Indígena (SasiSUS). Controle Social. Informação disponível em: https://saudeindigena1.websiteseguro.com/coronavirus/dsei/ Acesso em 16 de setembro de 2020. 


\section{Referências}

CAMPOS, Sandra Maria Christiani de La Torre Lacerda. Bonecas Karajá: modelando inovações, transmitindo tradições. Pontifícia Universidade Católica de São Paulo, 2007. (Tese doutorado)

CAMPOS, Sandra Lacerda. Bonecas Karaja. apenas um brinquedo? Revista do Museu de Arqueologia e Etnologia, São Paulo, 72: 233-248, 2002.

CHAGAS, Mário. Museus, memórias e movimentos sociais. Cadernos de Sociomuseologia, 41, 2011.

CHAGAS, Mário. "A história viva nos museus de favela”. In: Rio de encontros: novas perguntas e percepções sobre a cidade do Rio de Janeiro. Publicado em 06/10/2015. Disponível online em https://riodeencontros.wordpress.com/2015/10/06/a-historia-viva-nos-museus-de-favela/ , acesso em $21 \mathrm{de}$ setembro de 2020.

FARIAS, Joana Silva de Araújo. Modelando parentes: sobre a rede de relações das ritxo(k)o entre os Karajá. São Paulo: Universidade de São Paulo, 2014 (Dissertação de mestrado em Antropologia Social)

GONÇALVES, José Reginaldo Santos. Memória e patrimônio: ensaios contemporâneos. Regina Abreu; Mário Chagas (orgs.), Rio de Janeiro: DP\&A, 2003.

HARTMANN, Günther. Litjoko: puppen der Karaja, Brasilien. Leipzig: Staatliche Museen Preussischer Kulturbsitz / Museum für Völkerkunde Berlin, 1973.

LIMA FILHO, Manuel F.. "O Fluxo das coisas Karajá e a coleção William Lipkind do Museu Nacional: a construção de um diálogo intercultural”. In: Manuel Ferreira Lima Filho; Regina Abreu; Renato Athias. (Orgs.). Museus e atores sociais: perspectivas antropológicas. 1ed. Recife - Brasília: Editora da UFPE - ABA publicações, 2016. Pp. 171-188.

LIMA FILHO, Manuel Ferreira. Coleção William Lipkind do Museu Nacional: trilhas antropológicas Brasil-Estados Unidos. Mana 23(3): 473-509, 2017 - DOI http://dx.doi.org/10.1590/1678-49442017v23n3p473

LIMA FILHO, Manuel Ferreira. Relatório de atividades Pós-Doutorado. Goiânia, 2015. (Manuscrito não publicado)

LIMA FILHO, Manuel F.; CAMARGO, Telma Ferreira. Bonecas Karajá. Horizontes Antropológicos, ano 18, n. 38: 45-74, jul./dez. 2012.

LIMA, Nei Clara de; et al. Bonecas Karajá: arte, memória e identidade indígena no Araguaia. Dossiê Descritivo do modo de fazer ritxoko. Goiânia: Museu Antropológico, Universidade Federal de Goiás, IPHAN, 2011.

LIMA, Nei Clara de; LEITÃO, Rosani Moreira. Bonecas Karajá como Patrimônio Cultural do Brasil: da pesquisa à salvaguarda. Disponível online em https://ndh.ufg.br/up/322/o/Artigo5.pdf?1453825313, acesso em o8 de outubro de 2016.

LIMA, Nei Clara de; DUARTE CÂNDIDO, Manuelina Maria. Projeto de pesquisa Presença Karajá: cultura material, tramas e trânsitos coloniais. Goiânia: Museu Antropológico da UFG, 2016. 10 páginas. (Manuscrito não publicado)

MBEMBE, Achille. Nécropolitique. Raisons politiques, vol. 21, nº 1, 2006. 
MINISTÉRIO DO MEIO AMBIENTE. Caderno da Região Hidrográfica do Tocantins-Araguaia. Secretaria de Recursos Hídricos. Brasília: MMA, 2006. 132 p.

MORAES WICHERS, Camila Azevedo de. Sobre a Musealização de acervos inykarajá: desafios e possibilidades para uma prática decolonial. Habitus, Goiânia, v. 17, n.1, 53-76, jan./jun. 2019.

OLIVEIRA, João Pacheco de; SANTOS, Rita de Cássia Melo. "Introdução". In: OLIVEIRA, João Pacheco de; SANTOS, Rita de Cássia Melo (orgs.). De acervos coloniais aos museus indígenas: formas de protagonismo e de construção da ilusão museal. João Pessoa: Editora da UFPB, 2019. pp. 07-25.

RESENDE, Michelle Nogueira de. A representação do sobrenatural na cerâmica figurativa Karajá. Goiânia: Universidade Federal de Goiás, 2011. (Trabalho de Conclusão do Bacharelado em Ciências Sociais)

RESENDE, Michelle Nogueira de. As ceramistas Karajá e o processo de registro de suas bonecas de cerâmica como patrimônio cultural do Brasil. Goiânia: Núcleo Interdisciplinar de Estudos e Pesquisas em Direitos Humanos da Universidade Federal de Goiás, 2014. (Dissertação de Mestrado em Direitos Humanos)

RODRIGUES, Patrícia de Mendonça. "Transformando dor em arte: o ofício das ceramistas Karajá como forma de resiliência histórica”. In: SILVA, Telma Camargo da (org.). Ritxoko. Goiânia: Cânone, 2015. pp. 15-47.

RÚSSIO, Waldisa. "Sistema da Museologia (1983)". In: Bruno, Maria Cristina de Oliveira. (coord.). Waldisa Rússio Camargo Guarniéri: textos e contextos de uma trajetória profissional. vol. 1. São Paulo: Pinacoteca do Estado, ICOM-Brasil, 2010. pp. 127-136.

SILVA, Telma Camargo. Modos de fazer Boneca Karajá, circulação de conhecimento e a construção do território. Paper disponível online em http://nepi.ufsc.br/files/2013/11/Paper-Telma-Camargo-da-Silva-NEPI1.pdf acesso em 7 de outubro de 2016.

UNESCO. Recomendação para a Proteção e Promoção de Museus e Coleções sua Diversidade e seu Papel na Sociedade. Paris: UNESCO, 2015. Disponível online em http://unesdoc.unesco.org/images/0024/002471/247152por.pdf acesso em 29 de julho de 2017.

WHAN, Chang. Ritxoko. A voz visual das ceramistas Karajá. Universidade Federal do Rio de Janeiro. Escola de Belas Artes, 2010. (Tese de Doutorado)

XVIII Conferência Internacional do MINOM. Declaração de Córdoba - A Museologia que não serve para a vida não serve para nada. Córdoba (Argentina), 2017. Disponível em linha http://www.minom-icom.net/noticias/minom-cordoba-declaration-2017-es-pt-fr-en 